\title{
LIVRO DIGITAL E LITERACIA DAS MÍDIAS: UMA ANÁLISE DE "THE FANTASTIC FLYING BOOKS OF MR. MORRIS LESSMORE"
}

\author{
Gabriela Borges* \\ Isa Mestre
}

\begin{abstract}
RESUMO: Este artigo apresenta uma análise da aplicação digital The Fantastic Flying Books of Mr. Morris Lessmore, uma transcriação do curta-metragem de mesmo nome dirigida por William Joyce e Brandon Oldenburg e vencedora de Oscar de melhor curta-metragem em 2012. Procuramos abordar as mudanças pelas quais a literatura infantil está passando com a convergência das mídias e a conseqüente hibridização de linguagens, que lhe conferem uma nova forma de criar narrativas e uma nova forma de leitura, que implicam novos saberes e novas competências, bem como novas metodologias de análise de produtos midiáticos. Sendo assim, propomos uma reflexão sobre esta obra a partir do conceito de página-plano, que aproxima a linguagem cinematográfica da linguagem literária e hipermidiática e do conceito de obra aberta, que pode ser visto como um dos substratos na discussão sobre a literacia das mídias.
\end{abstract}

PALAVRAS-CHAVE: Literatura. Hipermídia. Literacia. Objeto-novo. Obra aberta.

\section{Introdução}

A proliferação de novos meios e a rapidez com que novos suportes se vão afirmando no universo comunicativo traz à tona a necessidade de uma reflexão acerca dos novos produtos culturais que agora nos são dados a conhecer e, mais concretamente, acerca das suas características.

Um desses produtos é o objeto em torno do qual procuraremos refletir ao longo deste artigo. The Fantastic Flying Books of Mr. Morris Lessmore, um livro interativo produzido por William Joyce e Brandon Oldenburg, sob a alçada da Moonboot Studios, se afirma, na sua gênese, como um desafio proposto pela literatura e, ao mesmo tempo, como um expoente de um novo tipo de literatura que começa a irromper no meio digital. Numa profícua relação com o universo

\footnotetext{
"CIAC- Centro de Investigação em Artes e Comunicação/ Universidade do Algarve/ Universidade Federal de Juiz de Fora. Imeio: gabriela.borges0@gmail.com

* CIAC- Centro de Investigação em Artes e Comunicação/ Universidade do Algarve/ Universidade Federal de Juiz de Fora. Imeio: isa mestre@hotmail.com
}

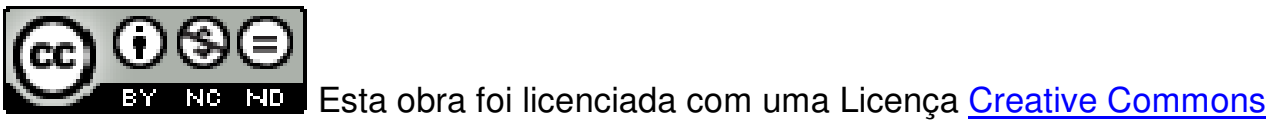

Texto Digital, Florianópolis, v. 9, n. 2, p. 109-121, jul./dez 2013. ANO. ISSNe: 1807-9288 
hipermidiático, esta obra propõe que nos questionemos sobre o que é o livro na medida em que promove um diálogo entre diversos gêneros e diversas mídias (texto, foto, vídeo) numa experiência que se revela lúdica, inventiva e criativa. Lançada a 31 de maio de 2011, pela Moonboot Studios, a aplicação para iPad The Fantastic Flying Books of Mr. Morris Lessmore, sucedeu o curta-metragem homônima e antecedeu o lançamento do livro.

Proporcionando uma inversão na ordem natural da maioria das recriações - da literatura para o cinema - esta aplicação veio mostrar, sobretudo, como uma mesma história pode trazer novo fôlego à narrativa e afirmar-se como um convite aos mais jovens para conhecer, interagir e desfrutar o prazer mágico da leitura.

Nesta produção, William Joyce e Brandon Oldenburg procuraram encontrar um modo criativo de explorar as potencialidades da tecnologia digital com o objetivo de trazer leitores ao caminho da literatura infantil. Focados na tarefa de contar histórias de um modo inovador, os criadores combinaram um curta-metragem animado, uma história de entretenimento e uma aplicação interativa em apenas um produto midiático.

A história, descrita pelos seus realizadores como uma "alegoria sobre o poder curativo dos livros", tem origem na experiência de Morris Lessmore, personagem central da trama que, ao ser subitamente acometido por um desastre natural, carimba o seu passaporte de entrada no mundo mágico dos livros. Inspirada em fontes que vão desde o Mágico de $O z$ ao furacão Katrina, a narrativa, que funciona como uma ode aos livros e à sua importância, tem como objetivo homenagear Bill Morris, editor de livros infantis e mentor de William Joyce.

\section{Análise da aplicação: o conceito de página-plano}

A aplicação é composta por 27 telas, que incluem elementos interativos com os quais o utilizador pode e deve entrar em contato ao longo do processo de leitura. Estas telas/páginas são o resultado de um processo de montagem entre o curtametragem e a aplicação, sendo a última construída com base nos elementos- 
chave da narrativa cinematográfica. Desta particularidade ressalta uma terminologia concebida especificamente, no processo de análise, para caracterizar o conceito de página neste novo paradigma interativo - a páginaplano.

Tendo em conta que todas as telas da aplicação se iniciam como vídeo, ou seja, se iniciam com imagem animada retirada estrategicamente do curta-metragem para integrar o produto hipermídia, faz sentido que consideremos o conceito de plano oriundo da estética audiovisual. Por outro lado, existe uma particularidade muito interessante. Em cada uma das páginas, após um primeiro excerto audiovisual, a imagem "congela" para que o leitor/utilizador possa se deter na tela o tempo que necessitar para explorar e poder assim interagir criativamente. Quando a imagem audiovisual congela, aquilo que assumíamos como um plano apresenta-se como uma página estática, à semelhança da página de qualquer outro livro, mas com a particularidade de possuir interatividade. Daí considerarmos adequado o termo página-plano para definir a relação entre estes dois elementos técnico-estéticos que se cruzam neste produto e muito concretamente no processo hipermídia que a ele é contíguo.

Deste modo podemos considerar, na generalidade, que a maioria das páginas da aplicação funciona de acordo com o seguinte esquema: imagem animada (excerto do curta-metragem) + imagem congelada (ilustração) + interação, sendo esta última de importância crucial no livro em análise. Vejamos: um claro exemplo é o modo como toda a aplicação é estruturada no sentido de exigir ação da parte do leitor/utilizador. Este é de tal modo impelido a participar que, se não o fizer, esvazia a história de sentido, uma vez que fica parado na narrativa sem possibilidades de avançar. Restam-lhe então duas hipóteses: ou se torna participante e interage com os elementos que the são apresentados na tela, abrindo portas ao desenvolvimento da narrativa ou, se optar por assumir apenas o papel de espectador, não interagindo com nenhum elemento, fica parado diante da primeira página numa atividade de mera contemplação. Sendo assim, o utilizador se vê obrigado a reagir para poder avançar de página-plano em páginaplano. 
A questão da ativação da página seguinte funciona também como um apelo ao desafio, na medida em que o leitor/utilizador não é convidado a abandonar a página em que se encontra enquanto não interagir de algum modo. Ou seja, só após realizar todas as interações possíveis numa determinada página é que o leitor/utilizador tem acesso, no canto superior direito, ao elemento que permite a passagem para a tela que se segue.

Toda a estrutura da aplicação é linear, uma vez que não são propostas interações propiciadas por ligações internas nem externas. A aplicação segue, desde o início até ao final uma estrutura lógica e contínua, que funciona em consonância com o desenrolar da história. Ao entrar na primeira página-plano o leitor/utilizador terá de percorrer todas as outras para chegar ao final da história. Embora seja dotada de uma série de interações, esta aplicação não nos propõe que escolhamos, por exemplo, entre dois caminhos. O percurso será sempre executado de modo linear, sobrando apenas alguma não-linearidade para o modo como cada leitor/utilizador interagirá com a aplicação. Embora a aplicação siga o percurso lógico e linear da narrativa, o leitor/utilizador é dotado, na sua experiência de leitura, de uma dose de não-linearidade, fruto da interação individual e única que desenvolve com o produto. Por exemplo, o leitor/utilizador A pode apenas descobrir um elemento para interagir em uma determinada página-plano enquanto o leitor/utilizador B pode descobrir todos os elementos existentes. Numa primeira leitura o leitor/utilizador $C$ pode interagir com poucos elementos, o que não significa que em leituras seguintes não esteja mais atento à questão da interação e encontre outros elementos. Estamos, portanto, perante um percurso linear em que a interatividade pode trazer alguma não-linearidade no modo de desfrutar esse mesmo percurso. Isto é particularmente importante se tivermos em conta que estamos diante de uma obra hipermidiática, fruto do cruzamento de diversas mídias digitais.

Como obra hipermidiática, The Fantastic Flying Books of Mr. Morris Lessmore, partilha das cinco características das mídias digitais apresentadas por MarieLaure Ryan (2004, p.338): reatividade e interatividade; potencialidade multimídia; potencialidade de conexão; signos voláteis e modularidade. Comecemos pela 
segunda característica apresentada pela autora e que se refere à capacidade das obras digitais agregarem "múltiplos canais sensoriais e semióticos" (Ryan, 2004, p.338), ou seja, o mesmo é dizer, a sua capacidade para reunir diversas mídias, com as suas respectivas propriedades, na formação de um novo produto hipermidiático.

Neste campo, a aplicação de The Fantastic Flying Books of Mr. Morris Lessmore assume-se como extremamente agregadora, no sentido em que reúne elementos do curta-metragem e da história escrita na qual tem origem para a criação de um produto que reúne linguagem visual, sonora, textual e hipermidiática.

A potencialidade de conexão é também passível de ser verificada na obra. Enquanto Ryan (2004, p.338) nos fala da capacidade que as mídias digitais têm de conectar máquinas e pessoas, unindo-as em ambientes virtuais, The Fantastic Flying Books of Mr. Morris Lessmore nos oferece outro exemplo de conexão, desta feita entre autor e utilizador. Trata-se de uma conexão que nunca se extingue devido ao cariz de atualização constante da aplicação. Ou seja, o fato de a aplicação estar constantemente a ser atualizada pelo autor mantém um laço com o leitor/utilizador que, ao descarregar a nova versão, procura novas surpresas. Por outro lado, ao ter acesso à aplicação, o leitor/utilizador serve-se da máquina, neste caso o iPad, interagindo com ela e, consequentemente, imergindo no universo virtual da história.

No que diz respeito à volatilidade dos signos, a obra em questão nos oferece um claro exemplo através das atualizações que são disponibilizadas ao leitor/utilizador e que visam uma reformulação constante da linguagem digital proposta pela aplicação. Deste modo, nunca estamos perante uma obra acabada, mas perante uma obra que está constantemente a ser atualizada e reescrita, o que proporciona uma dinâmica verdadeiramente extasiante.

A modularidade, também abordada por Lev Manovich (2001), está diretamente relacionada com o potencial unificador da hipermídia, que permite que um produto seja composto por módulos autônomos que podem ser trabalhados individualmente. No entanto, e embora a tenhamos guardado para último, a 
interatividade assume-se como um dos elementos fundamentais do universo hipermídia e talvez aquele que mais a diferencia dos restantes sistemas de hipertexto (RYAN, 2004, p. 338).

Para Ryan (2004, p. 339), e no que toca à participação do utilizador, estamos perante duas dicotomias, a participação interna vs. participação externa e o envolvimento exploratório vs. o envolvimento ontológico. A participação interna é caracterizada por um maior envolvimento do utilizador, que se assume como membro de uma realidade virtual, ou seja, "veste" a pele de uma personagem ou é identificado com um avatar. Por sua vez, a participação externa é marcada pelo fato de o utilizador se encontrar fora do mundo virtual, agindo como um poder que controla tudo o que acontece na ação ou navegando através de uma base de dados.

No caso de The Fantastic Flying Books of Mr. Morris Lessmore podemos considerar a participação do utilizador como externa, uma vez que este não se assume como nenhuma das personagens da trama nem é identificado com nenhum avatar, cabendo-lhe apenas entrar em contato, interativamente, com o percurso que é previamente determinado pelo criador da obra. Na verdade, ao percorrer esse caminho o utilizador está explorando a base de dados desenhada pelo autor no momento da criação.

Em relação à segunda dicotomia, podemos destacar uma oposição entre o envolvimento exploratório e o envolvimento ontológico. De acordo com Ryan (2004, p.339) o envolvimento exploratório é marcado pela liberdade do utilizador para navegar no interior da base de dados, sendo que a sua interação não interfere no rumo da história, não altera o enredo. Em poucas palavras, podemos afirmar que neste tipo de envolvimento o utilizador não tem qualquer impacto no modo como se desenrola o percurso no mundo virtual. No envolvimento ontológico, por sua vez, e em contraste, as decisões do utilizador contribuem para o desenvolvimento da história, marcando a escolha de caminhos no universo virtual. Sumariamente, podemos considerar que neste tipo de envolvimento é o utilizador que determina um dos diversos percursos possíveis, afetando por isso a trama e o modo como a história será desenvolvida. 
Neste sentido, e relativamente à segunda dicotomia apresentada por Ryan, reconhecemos em The Fantastic Flying Books of Mr. Morris Lessmore um envolvimento exploratório, pois o utilizador é livre para navegar no interior da história, interagindo com os elementos que o criador the propõe, sem que com isso altere ou interfira de algum modo na forma como esta se desenrola. $\mathrm{Na}$ verdade, o utilizador tem um papel de interação contributiva, ou seja, é ele que contribui para o avançar da história através do seu poder de interagir e de ir desvendando aos poucos os elementos interativos, sem que isso traga qualquer prejuízo para a história no que diz respeito ao seu significado ou ao percurso a efetuar. Portanto, estamos perante uma participação do tipo externa/exploratória que envolve o utilizador de modo a introduzi-lo na história como um visitante com poder para entrar em contato com os diversos elementos que a compõem e assistir ao seu desenvolvimento.

Outra das particularidades de The Fantastic Flying Books of Mr. Morris Lessmore é a complementaridade. Unindo imagem audiovisual, ilustração e literatura, cada página oferece ao leitor/utilizador o melhor de cada uma destas artes, proporcionando-lhe uma experiência na qual a imagem audiovisual cumprirá o seu papel de "mostrar", a ilustração dotar-nos-á do tempo necessário para observar e a literatura contar-nos-á a história daquilo que vemos.

Ainda neste sentido podemos ressaltar a possibilidade de um contato transversal com a obra que vai permitir simultaneamente o enriquecimento das literacias audiovisuais, visuais, textuais e, em última instância, das literacias interativas.

\section{Nova forma de se contar histórias}

Esta ampliação do modo de se contar e ler histórias leva-nos inevitavelmente rumo à ideia de que, com o aparecimento de novos meios de comunicação, também a literatura sofreu alterações e readaptações, abarcando hoje diversos tipos de textos que em muito diferem daquilo que essencialmente identificamos como literatura. Neste sentido, The Fantastic Flying Books of Mr. Morris Lessmore 
é a prova de que atualmente o livro divide espaço com outros suportes, trazendo novas possibilidades criativas para a literatura.

Tendo como base uma estrutura associativa, dinâmica e interativa, a literatura praticada nos meios digitais assume-se como irreverente e experimentalista, procurando explorar as potencialidades da própria literatura. Partilhando algumas das características encontradas na poesia concreta, como por exemplo o caráter visual da escrita, a literatura digital procura explorar as fronteiras da linguagem, aproveitando-se da visualidade do texto para criar uma experiência ativa que enriquece a relação com o objeto livro (apud Coelho, 2009, p.40).

Um dos expoentes máximos deste novo modo de narrar é aquilo que Góes (2003, p.19) denomina objeto-novo. De acordo com a autora, o objeto-novo é um tipo de livro que concentra "linguagens de natureza vária e variada", exigindo da parte do leitor um "olhar de descoberta", concretizado no ato da interação.

De modo básico, o objeto-novo apresenta as seguintes características: oferece textos plenos de significados e intertextualidades, de modo que, para fruir completamente a obra, o leitor tem que embrenhar-se nela; proporciona uma leitura lúdica que permite a aprendizagem através das situações retratadas na narrativa; efetiva o processo de significação através da relação entre o leitor e o texto, no nível sensorial, emocional e racional; permite potenciar a expressão criadora do leitor na medida em que no seu processo de interação the permite criar, inventar, relacionar e escolher.

$\mathrm{Na}$ sua raiz, o objeto-novo afirma-se como intersemiótico e intertextual, encaixando-se na categoria da literatura hipermidiática na medida em que relaciona diversas linguagens e diversos textos, proporcionando intersemiose a um elevado nível.

Enquanto o livro infantil comum propõe um diálogo entre texto e imagem, o objeto-novo sugere um relacionamento entre todas as linguagens que 0 compõem. Nele, fotografia, som, animação e ilustração funcionam em conjunto no processo de construção de significados. 
No entanto, esta construção de significados não está, na literatura hipermidiática, e mais concretamente no objeto-novo, unicamente dependente das linguagens utilizadas e do modo como estas se relacionam. Na verdade, também o leitor se assume como elemento determinante na construção de significado.

Para que a obra se complete e, essencialmente, para que a leitura seja eficaz, o leitor deve ter a habilidade de interpretar as diversas linguagens que a compõem e, perante essa interpretação, intervir. Esta intervenção, traduzida pela interação, é uma das grandes marcas deste tipo de literatura que vai ao encontro do conceito de obra aberta, de Umberto Eco (1962), que já identificava o leitor como um agente dinâmico no processo de leitura. Identificada pelo autor italiano como uma obra em que uma série de significados convergem, a obra aberta é definida, na sua essência, não como um produto acabado, com apenas um sentido e apenas um significado, mas como um produto por acabar, uma mensagem incompleta, uma obra constantemente em construção pelo leitor.

Aberta a quê? Aberta a quem? Essencialmente aberta ao mundo e, de acordo com Eco, aberta ao fruidor que, com a sua interação, a transforma, afirmando claramente o seu papel: ao invés de fruir passivamente a obra, ele tem a tarefa de completá-la, revivê-la, reformulá-la e compreendê-la no momento da interação, a partir da sua experiência. O leitor é a peça que completa o puzzle, a árvore da qual florescerão novas interpretações e novos significados. A cada vez que interage com a obra a mantém viva na sua essência, carregando-a com a sua perspectiva individual.

Assim, e ao longo deste percurso, o leitor vai obrigatoriamente captar não apenas os significados determinados ou previstos pelo autor da obra, mas vai também se tornar, através do processo de interpretação, um executante da obra que, tal como um músico que interpreta uma composição alheia, o fará de modo único e individual.

Neste contexto, e estabelecendo uma relação com os livros digitais, podemos afirmar que criador, obra e leitor formam uma tríade de interação contínua. $\mathrm{O}$ criador assume-se como o elemento número um do processo, na medida em que 
concebe a obra, mediada pelo computador, desenhando uma teia de percursos possíveis. Ao computador cabe o papel de executá-la, ou seja, executar a tarefa para o qual foi programado de acordo com as instruções do criador. Por seu turno, o leitor terá de seguir os caminhos que escolheu, todavia sempre condicionado ao universo de escolhas que lhe é oferecido pelo criador. Deste modo, o leitor da narrativa hipermidiática é também seu cocriador, tendo a oportunidade de reinterpretá-la e recriá-la.

Desta forma podemos considerar a literatura hipermidiática como um desafio a uma leitura renovada que coloca o leitor no centro do processo, transformando-o num agente. Neste sentido, a recepção se afirma como uma reinvenção que recupera a noção do leitor como construtor de sentidos e significados, oferecendo-Ihe a interatividade necessária para que deixe de ser apenas aquele que lê e se torne também aquele que interage, participa e escolhe.

É importante destacar que no atual panorama de convergência das mídias surgem novas formas de se contar histórias que têm como pressuposto não apenas outras formas criativas, mas também novos modos de leitura. Estas mudanças têm sido muito discutidas no campo de estudos da literacia das mídias e têm sido enfatizadas nos estudos desenvolvidos pela Comissão Europeia, nomeadamente no contexto de educação formal e não formal portuguesa. Esta necessidade acrescida de se repensar e refletir sobre a produção cultural recente em função do desenvolvimento da tecnologia digital muitas vezes leva a que se proponham novas formas para se pensar antigas questões.

Neste artigo mostramos que a aplicação para iPad The Fantastic Flying Books of Mr. Morris Lessmore apresenta novos modos narrativos que requerem outro tipo de interação por parte do leitor em relação à literatura não digital. Porém, podemos ressalvar que Eco (1962) já propunha o conceito de obra aberta, que requer a ressignificação por parte do leitor, que neste caso termina a obra, num panorama pré-digital. No entanto, no livro digital, o leitor/utilizador ressignifica a obra a partir da escolha de elementos hipermidiáticos, de um modo diferenciado daquele que pensou Eco num panorama pré-digital. Sendo assim, por um lado, reafirmamos a contemporaneidade do pensamento do teórico italiano e, por outro 
lado, ressaltamos algumas diferenças no que diz respeito à experiência estética que a tecnologia digital propiciou.

Neste mesmo sentido, é interessante destacar que já encontramos no conceito de obra aberta os substratos da discussão sobre as competências associadas à literacia das mídias, que tem sido definida como a capacidade de acessar, analisar e avaliar o poder de imagens, sons e mensagens que confrontam 0 sujeito contemporâneo, assim como comunicar de forma competente através das mídias disponíveis.

\section{Considerações Finais}

Portanto, podemos afirmar que The Fantastic Flying Books of Mr. Morris Lessmore pode ser considerada uma obra hipermidiática e, mais concretamente, um objeto-novo que se afirma como um livro que se diferencia do livro impresso tanto no que diz respeito ao processo de criação quanto à experiência de leitura.

Se estabelecermos uma relação entre as características do objeto-novo e a experiência de leitura de The Fantastic Flying Books of Mr. Morris Lessmore facilmente perceberemos que ambos se tocam. A plenitude significativa e intertextual referida por Góes (2003) é um dos elementos-chave da obra em análise. De cariz intensamente metafórico, The Fantastic Flying Books of Mr. Morris Lessmore rapidamente coloca o leitor numa posição ativa de procura, interpretação e reinterpretação dos significados que veicula. Além disso, a sua relação de intertextualidade com outras obras é também um ponto forte na medida em que expande as suas potencialidades, se tornando ainda mais aberta e servindo de farol para o conhecimento de outros produtos culturais. Ao fazê-lo, a obra está, mais uma vez, e de acordo com os princípios da hipermídia, funcionando de modo associativo e relacional.

Também a componente lúdica estabelece uma relação entre The Fantastic Flying Books of Mr. Morris Lessmore e o objeto-novo. Com pelo menos duas páginas em que a máxima do "aprender brincando" impera, a aplicação assume-se como extremamente educativa. Além do ensinamento que a história de Morris Lessmore 
alastra para a narrativa, são muitos os momentos em que o utilizador sente, através do poder da interação, que pode "brincar" com todos os elementos que se apresentam perante o seu olhar.

Por último, a obra assume-se também como potenciadora de uma experiência criativa e criadora no sentido em que, apesar do leitor/utilizador não poder alterar o rumo da narrativa ou interferir diretamente nela através da sua ação, ele está constantemente a interpretá-la e reinterpretá-la no processo de leitura, "carregando-a" ou dotando-a dos seus sentimentos, emoções e vivências.

Sumariamente, podemos assumir The Fantastic Flying Books of Mr. Morris Lessmore, na sua globalidade, como uma plataforma comum através da qual obra, criador e fruidor se encontram na construção de um objeto-novo, que visa explorar as fronteiras de todas as linguagens que o constituem.

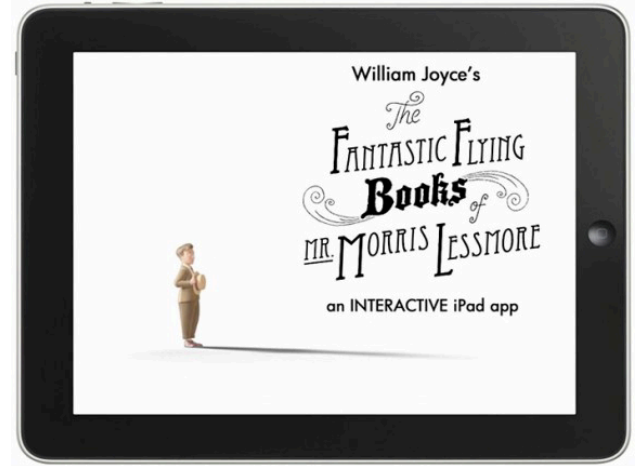

Screenshot da Aplicação no 1

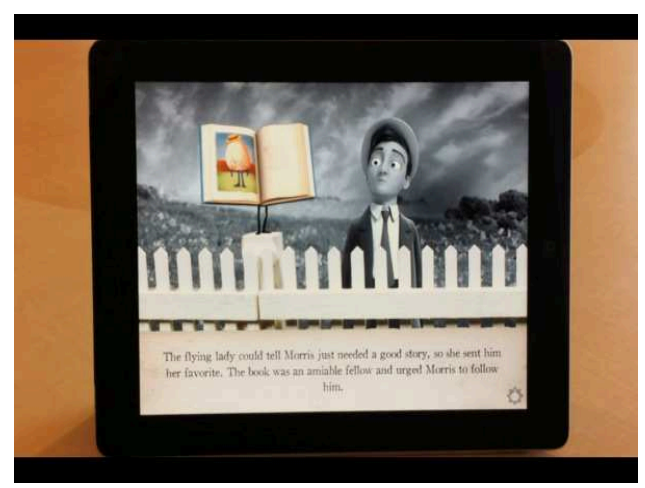

ScreenShot da Aplicação no3

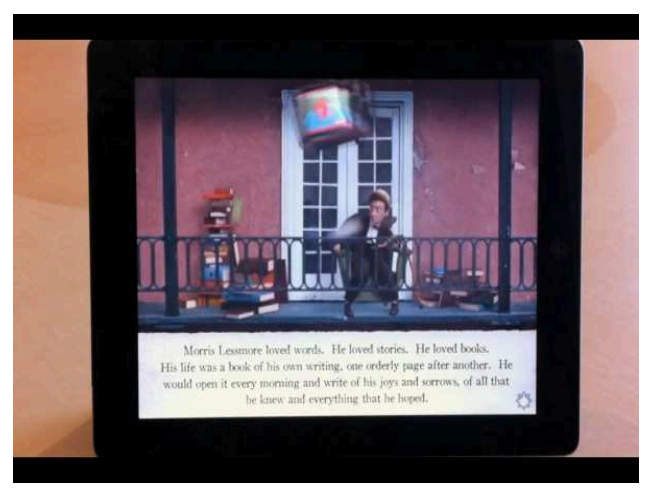

Screenshot da Aplicação no 2

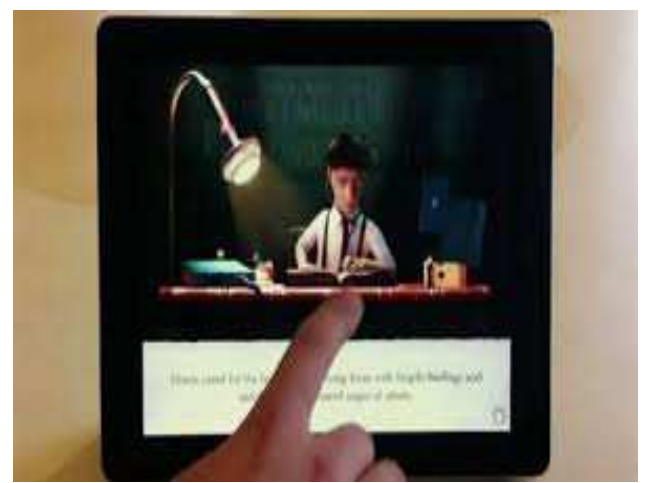

ScreenShot da Aplicação no4 


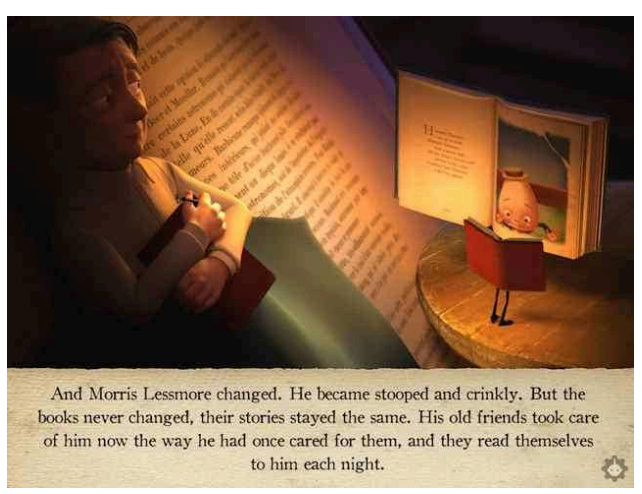

ScreenShot da Aplicação no5

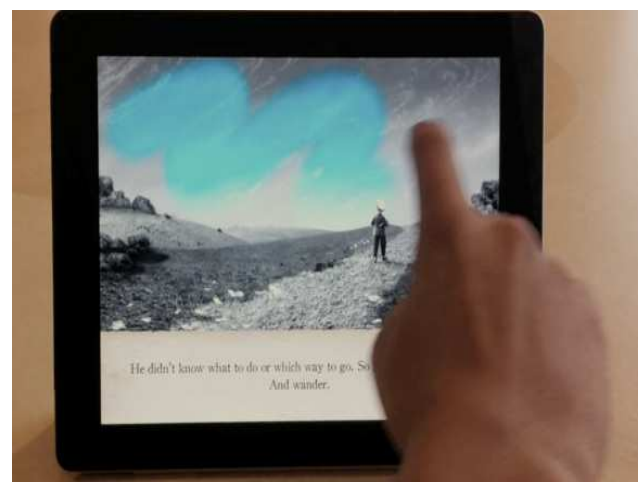

ScreenShot da Aplicação no6

\section{DIGITAL BOOK AND MEDIA LITERACY: AN ANALYSIS OF THE FANTASTIC FLYING BOOKS OF MR. MORRIS LESSMORE}

ABSTRACT: This article analyses the digital application The Fantastic Flying Books of Mr. Morris Lessmore, a transcreation of the homonymous short film directed by William Joyce and Brandon Oldenburg and Best Short Film Oscar Winner in 2012. We intend to discuss children's literature changes due to media convergence and subsequent hybridization of languages, providing it with new narrative modes and ways of reading that involve diverse types of knowledge and skills, and also new methodologies to analyse media products. Thus, we will analyse this work through the concept of "página-plano" [page-shot] that relates audiovisual language to literary and hypermedia languages, and also to the concept of open work, which can be perceived as one of the elements in the discussion about media literacy.

KEYWORDS: Literature. Hypermedia. Literacy. New-object. Open work.

\section{REFERÊNCIAS}

ECO, Umberto. Obra Aberta. 1ํㅡㄹ ed. São Paulo: Perspectiva,1962.

GÓES, Lúcia Pimentel. Olhar de descoberta: proposta analítica de livros que concentram várias linguagens. São Paulo: Paulinas, 2003.

MANOVICH, Lev. The language of new media. Massachusetts: MIT Press, 2001.

NASCIMENTO, José Augusto. Literatura infantil e cultura hipermidiática: relações sócio-históricas entre suportes textuais, leitura e literatura. Dissertação de mestrado apresentada a Faculdade de Filosofia, Letras e Ciências Humanas da Universidade de São Paulo, São Paulo: 2009. Disponível em <http://migre.me/h0A3u> Acesso em: 19 set. 2013.

RYAN, Marie-Laurie (Org.). Narrative across Media: The Languages of Storytelling. $1^{a}$ ed. Lincoln e Londres: University of Nebraska Press, 2004.

Texto recebido em 09/10/2013.

Texto aprovado em 29/11/2013. 